\title{
Technological and construction features of modular reinforced concrete foundation designing for various high-rise structures
}

\author{
Linar Sabitov*1, Aleksandr Mayilyan², Levon Mayilyan², Serdar Yazyev², Oleg Radaykin³, \\ Leisan Akhtyamova ${ }^{1}$ \\ ${ }^{1}$ Kazan (Volga region) Federal University, 420008, Kazan, Russia \\ ${ }^{2}$ Don State Technical University, 344002, Rostov-on-Don, Russia \\ ${ }^{3}$ Kazan state university of architecture and civil engineering, 420043, Kazan, Russia
}

\begin{abstract}
The paper proposes a new type of modular collapsible reinforced concrete foundation for steel support of various types of structures: power lines, wind power plants, billboards, traffic lights, etc. The foundation has the shape of a cross-hammer in the plan and consists of separate modules manufactured at the factory and connected to each other by concrete dowels and tie bolts on the construction site. At the same time, this technological approach makes it possible to obtain more stable (uniform) strength and deformation properties of both the individual module and the assembled foundation as a whole. Reducing the material consumption is achieved by creating a cavity in each typical module and filling it with local inert material (soil). The Central module has an anchor device for joining with the support according to the type of flange connection. This device, along with the use of conventional anchor bolts, involves filling the Central module with non-shrinkable fast-hardening steel-fiber concrete. Thus, the positive result of the proposed solution is to increase the bearing capacity of the Foundation as a whole, increase the strength and stiffness of its main joints, and simplify installation in comparison with traditional approaches to construction. A comparative calculation of the foundations of the proposed and standard known solutions showed the effectiveness of the first one by at least $17.2 \%$.
\end{abstract}

\section{Introduction}

Rightfully, the foundation is the main element of any structure that is responsible for its constructive safety as a whole. At the same time, the cost of its manufacture in the structure of the total cost of the structure can reach $50 \%$ or more. This is more typical for steel poles' foundations of power lines, wind turbines, billboards, traffic lights, etc. Therefore, the task associated with the search for optimal structural solutions of foundations for the listed structures is relevant.

\footnotetext{
*Corresponding author: sabitov-kgasu@mail.ru
} 


\section{Materials and methods}

Obtaining an optimal foundation design in the work is based on the following principles:

1 - foundation assembly at the construction site from separate standard modules manufactured at the factory allows to obtain more stable (uniform) strength and deformation properties of both a single module and the assembled foundation as a whole;

2 - material consumption reduction due to the formation of a cavity in each module and filling it with local inert material (soil);

3 - foundation mass distribution in the plan in accordance with the action of maximum efforts (creating a foundation with a cross-type cross-section in the plan);

4 - labor costs' reduction at the manufacturing stage at the plant or landfill due to the use of high-performance machines and mechanisms without laborious manual operations;

5 - labor costs' reduction at the installation stage without the participation of special lifting mechanisms, which is ensured by the low weight of a separate module, which can be mounted manually.

\section{Results and discussion}

In the patent [1], a constructive solution is proposed for the foundation under the billboards' supports. It is a prismatic reinforced concrete volume, manufactured in a prefabricated or monolithic version. The foundation is equipped with anchor bolts for docking with the support. The disadvantage of this solution is its high material consumption and relatively large size, which significantly increases the cost of transportation and installation.

The foundation consisting of separate hollow modules - boxes [2] looks more effective. Adjacent modules are bolted together. The central module contains a special anchor device for docking with the support. To increase the stability of the structure as a whole, the cavities of the modules are filled with an inert material (local soil). In the article, this decision is considered as an analogue. But it also has disadvantages:

- a small moment of foundation area resistance due to the irrational distribution of the material relative to the center of gravity of the structure;

- high complexity and flexibility of connecting modules to each other;

- low reliability of the support junction with the foundation.

In this regard, the aim of this work is to eliminate the above listed disadvantages due to: increasing the bearing capacity of a modular concrete foundation under the support as a whole, increasing the strength and rigidity of its main joints, as well as simplifying the installation of the foundation.

To achieve this, the following three foundation design improvements are proposed:

- the concrete modules' location relative to each other in the plan is taken so that they form a cross-section in the form of a "cross-hammer" [3], whose moment of resistance is greater than that of a rectangular section with the same area [4];

-on the outer surface of two adjacent concrete faces of each module vertical ridges are made, vertical grooves are made on two other adjacent faces; they are necessary for joining with the corresponding grooves and ridges of other modules, while the vertical grooves of each module are bounded from below by horizontal partitions - mounting limiters; this simplifies the centering and alignment of individual modules with each other during installation and provides high strength and rigidity of their connection to each other;

- the central module, which contains the anchor device for docking with the support, is filled with non-shrink fast-hardening steel fiber concrete, which significantly increases the strength and stiffness of this joint due to the high operational qualities of steel fiber concrete [5].

The design of the proposed foundation is shown in Fig. 1-4. 


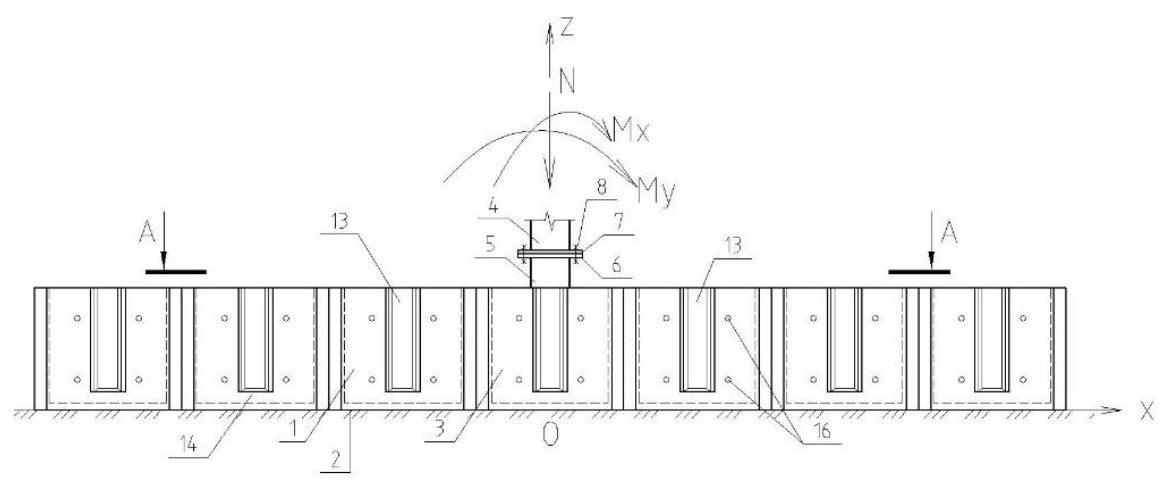

Fig. 1. Front view of the modular foundation at the time with the loads application scheme

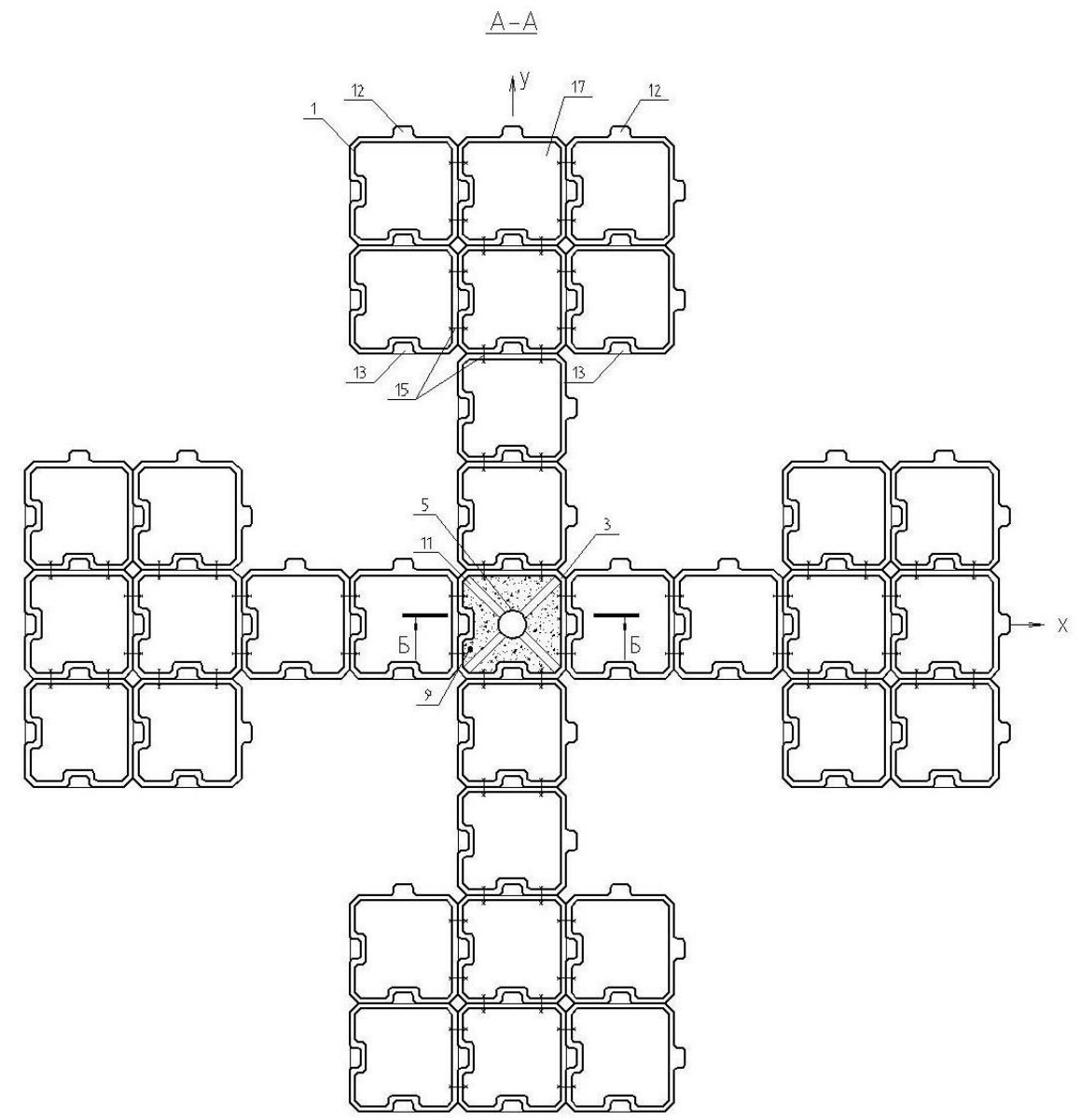

Fig. 2. Top view 


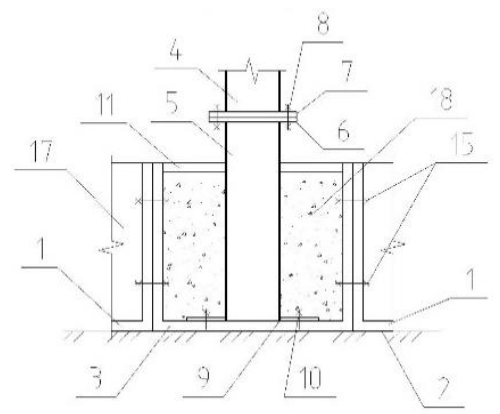

Fig. 3. The central module at the junction of the support and the foundation

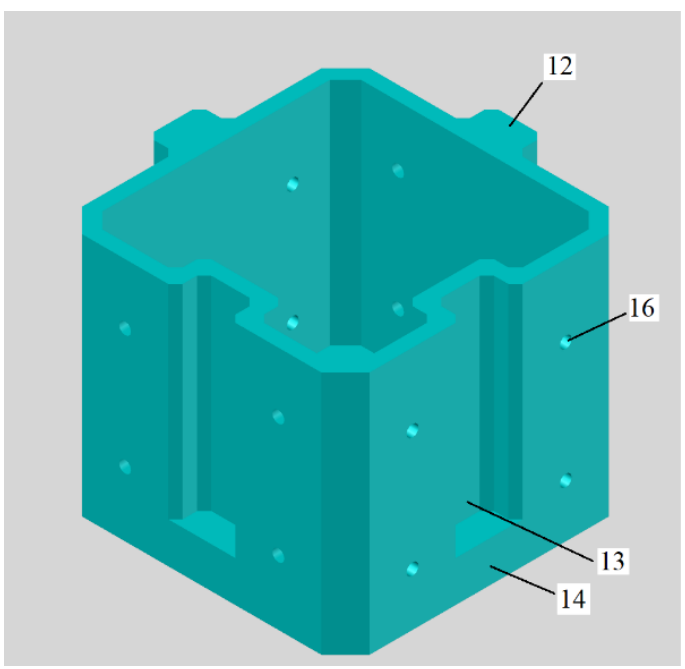

Fig. 4. Isometric view of an ordinary module

Fig. 1 shows a general view of the foundation; Fig. 2 shows a longitudinal section; Fig. 3 shows a section along the central module; Fig. 4 shows a perspective view of a typical module. Designations adopted in the figures: 1 - typical module; 2 - soil base; 3 - reference module; 4 - steel support; 5 - hollow barrel of the anchor device; 6 - upper flange; 7 - bolt screed; 8 - counterflange; 9 - lower flange; 10 - anchor bolts; 11 - steel struts; 12 - vertical concrete ledges; 13 - vertical grooves in concrete faces; 14 - horizontal partitions installation limiters; 15 - fixing bolts; 16 - holes for bolts; 17 - backfilling with an inert material (soil); 18 - filling non-shrink fast-hardening steel fiber concrete.

Calculation of the foundation of the proposed type can be carried out on the basis of computer simulation of the system "base soil - foundation - steel support" in Ansys software $[6,7]$ using concrete state diagrams $[8,9]$. The manufacturing technology and properties of the concrete used to fasten the support with the foundation are described in [10].

A consistent assessment of the concrete modular foundation effectiveness of the proposed type can be obtained by comparing it with an analogue having a rectangular (as a special case, square) section of the sole. Such an assessment can be obtained in two ways:

1 - if the moments of cross section resistance for the foundations' sole of both types $W_{x, 1}=W_{x, 2}$ are equal, the most effective sectional area of the sole will be less than $\left(A_{f 1}<A_{f 2}\right.$ ), which will indicate a reduced consumption of materials for its manufacture; 
2 - with the same cross-sectional area of the foundations' sole of both types $A_{f 1}=A_{f 2}$ (the same consumption of materials for manufacturing), the most effective moment of sole resistance will be greater $\left(W_{x, 1}>W_{x, 2}\right)$.

Let us mark the foundations' dimensions of both types as $b_{f 1}, l_{f 1}$ and $b_{f 2}, l_{f 2}$, respectively. Module size is marked by $a$.

Moreover, the number of modules required to form the long side of modular foundation new type is equal to $n_{l}$ the short one $-n_{b}$; the number of modules for each "crutch" of the cross-hammer cross section is equal $n_{k}$, the number of rows in each "crutch" is $n_{r}$.

Let the cross-section dimensions of the foundations in two mutually perpendicular directions are equal. Then the cross-sectional area of the sole is equal to:

- for a new type foundation $A_{f 1}=a\left(b_{f 1}+l_{f 1}\right)-a^{2}+4 n_{k} a^{2}$;

- for an existing analogue $A_{f 2}=b_{f 2} l_{f 2}$.

The moments of resistance for them are equal to:

$$
\begin{aligned}
& W_{x, 1}=\frac{a l_{f 1}^{2}}{6}+\frac{\left(b_{f 1}-a\right) a^{3}}{6 l_{f 1}}+\frac{4 n_{k}}{l_{f 1}}\left[\frac{n_{r}^{2} a^{4}}{12}+a^{2}\left(\frac{l_{f 1}-n_{r} a}{2}\right)^{2}\right]+\frac{4 n_{k}}{l_{f 1}}\left[\frac{n_{r} a^{4}}{12}+a^{2}\left(\frac{n_{k} a}{4 n_{r}}+\frac{a}{2}\right)^{2}\right] \\
& -W_{x, 2}=\frac{b_{f 2} l_{f 2}^{2}}{6} .
\end{aligned}
$$

As an example in Fig. 5 a foundation with a cross-hammer section consisting of 49 modules is considered. Its square counterpart, consisting of the same number of modules (that is, with the same sole area), will have dimensions in terms of $7 \times 7$ modules.

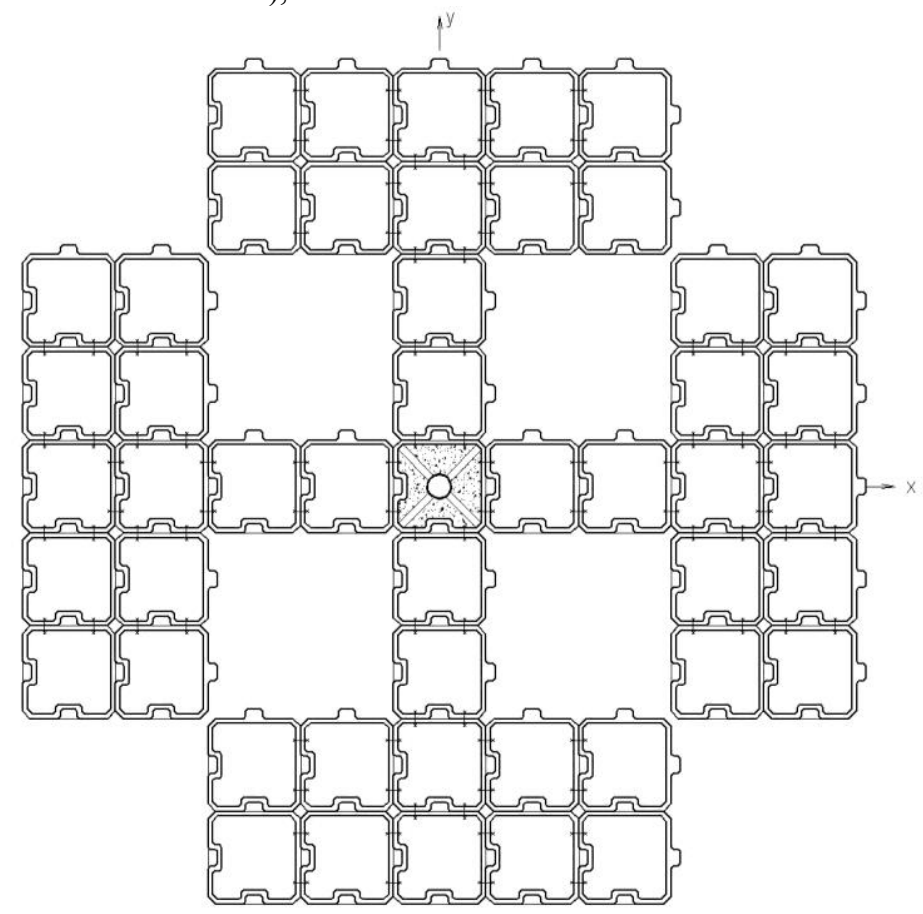

Fig. 5. The foundation of the proposed type, consisting of 49 modules 
The overall dimensions of the foundations are equal to:

1 type $-b_{f 1}=l_{f 1}=9 a=9 \cdot 0.6=5.4 \mathrm{~m}$;

2 type $-b_{f 2}=l_{f 2}=7 a=7 \cdot 0.6=4.2 \mathrm{~m}$.

Sole areas are equal:

1 type $-A_{f 1}=0.6 \cdot(5.4+5.4)-0.6^{2}+4 \cdot 8 \cdot 0.6^{2}=17.64 m^{2}$; either

$A_{f 1}=49 a^{2}=49 \cdot 0.6^{2}=17.64 \mathrm{~m}^{2}$;

2 type $-A_{f 2}=4.2 \cdot 4.2=17.64 \mathrm{~m}^{2}$.

The corresponding resistance moments are:

$$
\begin{aligned}
& W_{x, 1}=\frac{0.6 \cdot 5.4}{6}+\frac{(5.4-0.6) \cdot 0.6^{3}}{6 \cdot 5.4}+\frac{4 \cdot 8}{5.4} \cdot\left[\frac{2^{2} \cdot 0.6^{4}}{12}+0,6^{2} \cdot\left(\frac{5.4-2 \cdot 0.6}{2}\right)^{2}\right]+ \\
& +\frac{4 \cdot 8}{5.4}\left[\frac{2 \cdot 0.6^{4}}{12}+0.6^{2} \cdot\left(\frac{12 \cdot 0.6}{4 \cdot 2}+\frac{0.6}{2}\right)^{2}\right]=14.468 \mathrm{~m}^{3} \\
& -W_{x, 2}=\frac{4.2 \cdot 4.2^{2}}{6}=12.348 \mathrm{~m}^{3} .
\end{aligned}
$$

Thus, we have $\frac{W_{x, 1}}{W_{x, 1}}=\frac{14.468}{12.348}=1.172$ - so many times (by $17.2 \%$ ) the bearing capacity

of the foundation of the proposed type is higher than that of its analogue at the same consumption of materials. This value will be the greater, the farther apart the serifs are distributed at the ends of the cross-hammer section, which is possible, however, only to a certain limit, due to the strength of both crossbars of the cross-hammer.

Another advantage of the proposed foundation is the increased resistance of the modules' connection to shear forces due to the concrete key formation.

Let the cross section of the concrete tongue (protrusion) $h_{\mathrm{sh}} \times b_{\mathrm{sh}}$, then the shear force that it can absorb is equal to $T=R_{s h} b_{s h} h_{s h}, R_{s h} \approx 2 R_{b t}$, where $R_{s h}, R_{b t}$ are the shear and tensile strength of concrete, respectively. The equivalent diameter of the bolts that the key can replace is equal to $d_{s w}=\sqrt{\frac{2 R_{b t} b_{s h} h_{s h} n_{s}}{4 \pi R_{s w}}}$.

For example, let us consider that the modules are made of concrete of class B25 with $R_{b t}=1.05 \mathrm{MPa}$, have protrusions (dowels) of size $\mathrm{h}_{\mathrm{sh}} \times \mathrm{b}_{\mathrm{sh}}=820 \times 220 \mathrm{~mm}$. The modules are fastened with four bolts $\left(n_{s}=4\right)$ for shear, crumple, and tensile calculations. The bolts are made of class $4.6 \mathrm{~s}$ steel with $R_{s w}=170 \mathrm{MPa}$. Then the equivalent diameter is equal to $d_{s w}=\sqrt{\frac{2 \cdot 1.05 \cdot 0.22 \cdot 0.82 \cdot 2}{4 \cdot 3.14 \cdot 170}} \cdot 10^{3}=18.8 \approx 18 \mathrm{~mm}$.

\section{Summary}

A new type of modular reinforced concrete foundation for a steel support is proposed for various types of structures: power lines, wind power plants, billboards, traffic lights, etc. The technical result consists in increasing the bearing capacity of the foundation as a whole, increasing the strength and rigidity of its main joints, as well as simplifying the installation of the foundation. A comparative calculation of the bearing capacity of the foundations of 
the proposed and standard well-known solutions showed the effectiveness of the first not less than $17.2 \%$.

\section{References}

1. I.L. Kuznetsov, G.N. Shmelev, A.V. Isaev, M.V. Kozlov, Billboard, Patent RF, no 2243596, 2004.

2. I.L. Kuznetsov, D.M. Khusainov, Collapsible Foundation for support, Patent RF, no 2625060, 2019.

3. Crutch cross. Information on https://ru.wikipedia.org/wiki/Костыльный_крест (date of treatment: 01.01.2020).

4. G.S. Pisarenko, Resistance of materials (Vischa SHKOLA, Kiev, 1986).

5. M.G. Gabidullin, R.Z. Rakhimov, L.R. Badretdinov, A.N. Gabidullina, O.V. Stoyanov, Bulletin of the Kazan technological University, 17, 51-56 (2013).

6. L.S. Sabitov, I.L. Kuznetsov, I. R. Badretdinov, O.V. Radaykin, Bulletin of civil engineers, 6 (71), 37-44 (2018).

7. Yu.M. Strelkov, O.V. Radaykin, L.S. Sabitov, I.L. Kuznetsov, Construction mechanics and calculation of structures, 1, 71-79 (2019).

8. O.V. Radaykin, Bulletin of civil engineers, 6, 71-78 (2017).

9. L.R. Mailyan, E.I. Ivashchenko, Bulletin of Russian state social University, 4, 128132 (2006).

10. L.R. Mailyan, A.V. Nalimova, A.L. Mailyan, E.S. Engineering Bulletin of the Don, 4 (18), 573-580 (2011). 